University of New Hampshire

University of New Hampshire Scholars' Repository

Crimes Against Children Research Center

Research Institutes, Centers and Programs

$6-2000$

\title{
Characteristics of Crimes Against Juveniles
}

\author{
David Finkelhor \\ University of New Hampshire - Main Campus, David.Finkelhor@unh.edu \\ Richard Ormrod \\ University of Northern Colorado
}

Follow this and additional works at: https://scholars.unh.edu/ccrc

Part of the Sociology Commons

\section{Recommended Citation}

Finkelhor, David \& Ormrod, Richard. Characteristics of crimes against juveniles. Juvenile Justice Bulletin NCJ179034. (pgs. 1-11). Washington, DC: US Government Printing Office.

This Article is brought to you for free and open access by the Research Institutes, Centers and Programs at University of New Hampshire Scholars' Repository. It has been accepted for inclusion in Crimes Against Children Research Center by an authorized administrator of University of New Hampshire Scholars' Repository. For more information, please contact Scholarly.Communication@unh.edu. 


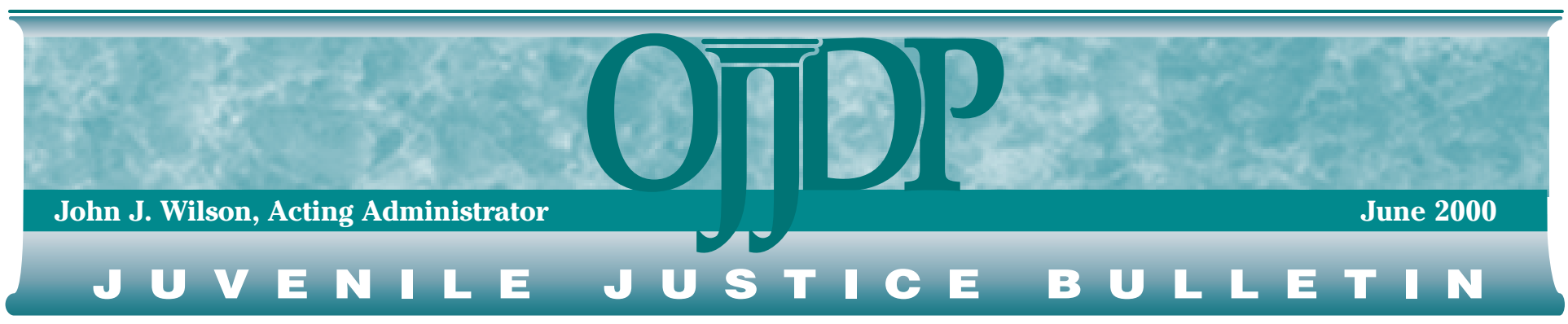

\section{Characteristics of Crimes Against Juveniles}

\section{David Finkelhor and Richard Ormrod}

The Office of Juvenile Justice and Delinquency Prevention (OJJDP) is committed to improving the justice system's response to crimes against children. OJJDP recognizes that children are at increased risk for crime victimization. Not only are children the victims of many of the same crimes that victimize adults, they are subject to other crimes, like child abuse and neglect, that are specific to childhood. The impact of these crimes on young victims can be devastating, and the violent or sexual victimization of children can often lead to an intergenerational cycle of violence and abuse. The purpose of OJJDP's Crimes Against Children Series is to improve and expand the Nation's efforts to better serve child victims by presenting the latest information about child victimization, including analyses of crime victimization statistics, studies of child victims and their special needs, and descriptions of programs and approaches that address these needs.

Until recently, it has been difficult to obtain a national statistical picture of juvenile crime victimization. The Uniform Crime Reporting (UCR) system, which has served as the Nation's primary source of information about crime since 1929, has never collected information or reported crimes by age of victim, with the exception of homicides. The National Crime Victimization Survey (NCVS), the victim self-report survey conducted by the U.S. Department of Commerce, Bureau of the Census on behalf of the U.S. Department of Justice, Bureau of Justice Statistics for the past 20 years, has collected data only on crimes occurring to persons 12 years of age or older. Consequently, even such a basic fact as the percentage of all violent crimes that are committed against juveniles (youth ages 17 and younger) has been unavailable.

The Federal Bureau of Investigation's (FBI's) developing National IncidentBased Reporting System (NIBRS), however, does provide detailed statistical information about juvenile victims of reported crimes. As more jurisdictions begin to participate in NIBRS, the outlines of a national picture of juvenile crime victims are beginning to emerge. Even though NIBRS is far from a comprehensive national data system, the fact that only partial data were available previously makes it particularly useful to see what information about juvenile victims can be gleaned from this system.

\section{From the Administrator}

The FBI's Uniform Crime Reporting (UCR) system and the Bureau of Justice Statistics' National Crime Victimization Survey do not collect information about crimes committed against persons under 12 years of age and thus do not provide a comprehensive picture of juvenile crime victimization. Designed to replace UCR as the national database for crimes reported to law enforcement, the FBl's National Incident-Based Reporting System (NIBRS) includes detailed data about juvenile victims.

This Bulletin reviews data from the 1997 NIBRS data file that pertain to juvenile victims, revealing that while juveniles made up 26 percent in the population of the 12 States participating in NIBRS in 1997, they accounted for only 12 percent of the reported crime victims. At the same time, however, 71 percent of all sex crime victims and 38 percent of all kidnaping victims reported to NIBRS were juveniles.

Although the data collected from the States participating in NIBRS in 1997 were not necessarily representative of the Nation as a whole, they represent a considerable number of reported crimes and thus constitute an invaluable resource for crime analysis. As the Bulletin's authors conclude, NIBRS should prove a crucial tool in years to come for researchers and practitioners seeking to improve public policies regarding juvenile crime victims.

John J. Wilson

Acting Administrator 
An analysis of 1997 NIBRS data from jurisdictions in 12 States reveals some key findings:

- Juveniles make up 12 percent of all crime victims known to police, including 71 percent of all sex crime victims and 38 percent of all kidnaping victims (figure 1).

- Simple assault is the most commonly reported crime against juveniles, constituting 41 percent of all juvenile victimizations reported to police (figure 2). Sexual offenses make up 12 percent, aggravated assaults 11 percent, and kidnapings 1 percent of all the crimes against juveniles reported to police.

- Girls predominate as victims of sex offenses and kidnaping, but boys predominate as victims of all other crimes.

- Children under age 12 make up approximately one-quarter of all juvenile victims known to police and at least one-half of the juvenile victims of kidnaping and forcible sex offenses.

- Adult offenders are responsible for 55 percent of juvenile victimizations, most disproportionately for kidnaping, sex offenses, and the victimizations of children younger than 6 and older than 15 .

- Family perpetrators make up 20 percent of the offenders against children, but they make up a majority of offenders against children under age 4 and are disproportionately represented among kidnapers and sex offenders.

\section{NIBRS Data on Juvenile Victims}

NIBRS is designed to become the national statistical database on crimes coming to the attention of law enforcement agencies. It collects more detailed information about individual crimes, victims, perpetrators, and crime characteristics than is available from the Uniform Crime Reporting program, the system it is intended to replace.

Because NIBRS data include the age of juvenile victims (to the nearest year in most cases), victim age is one of the important new variables that NIBRS makes available for the profiling of crime. NIBRS also provides detailed information on other victim characteristics, crime type, and victimization circumstances. Data are collected on numerous categories of crime, including homicide, assault, kidnaping, robbery, and sexual assault, and on specific offenses within each category.

Figure 1: Juvenile versus Adult Victimization, by Type of Crime and Victim's Age Group

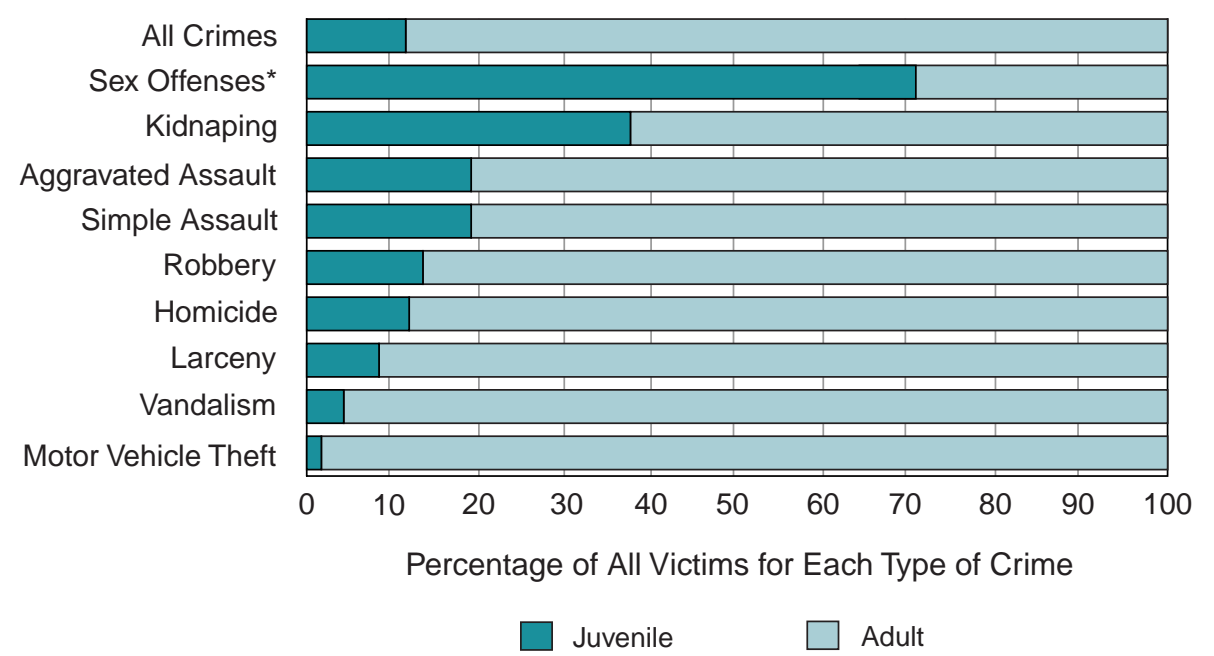

* Sex offenses against juveniles include forcible (64 percent) and nonforcible (7 percent) offenses.

Source: Federal Bureau of Investigation (1997), National Incident-Based Reporting System (NIBRS), (12 States only), Computer file, Tabulations undertaken by Crimes against Children Research Center, Washington, DC: U.S. Department of Justice, Federal Bureau of Investigation.

\section{Figure 2: Juvenile Victimization, by Type of Crime}

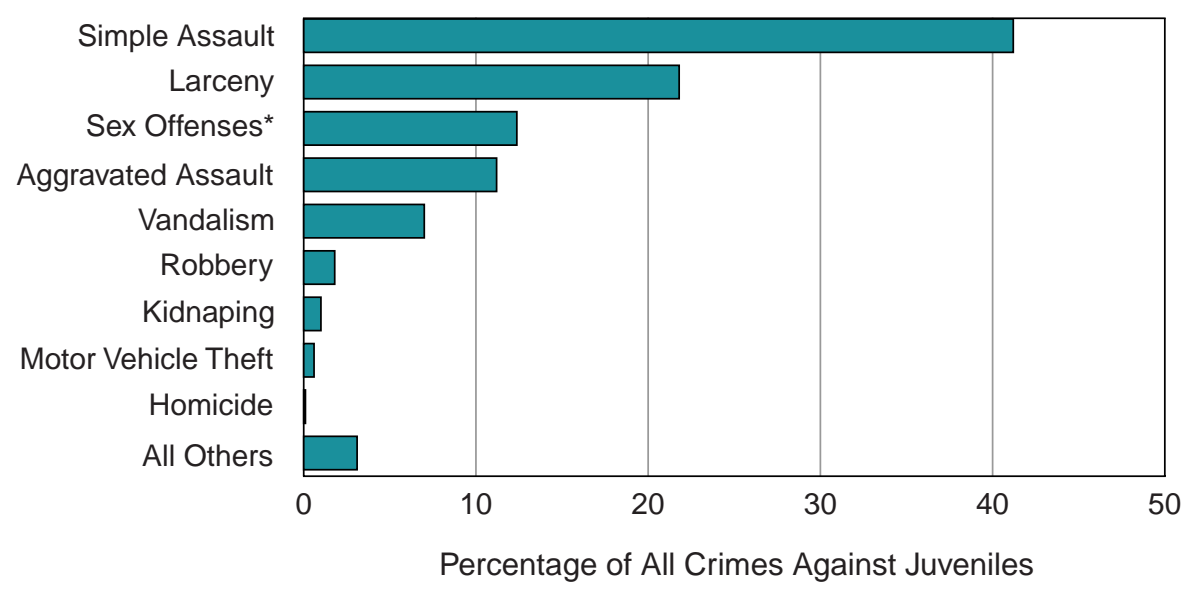

* Sex offenses against juveniles include forcible (11 percent) and nonforcible (1 percent) offenses.

Source: Federal Bureau of Investigation (1997), National Incident-Based Reporting System (NIBRS), (12 States only), Computer file, Tabulations undertaken by Crimes against Children Research Center, Washington, DC: U.S. Department of Justice, Federal Bureau of Investigation.

For example, assault can involve aggravated assault, simple assault, or intimidation, while sexual assault encompasses forcible rape, forcible sodomy, sexual assault with an object, and forcible fondling. NIBRS also collects information on nonviolent crimes that can be linked to indi- vidual victims, including theft and vandalism, and nonforcible sex offenses such as statutory rape and nonforcible incest. Although homicide is the most serious violent crime and NIBRS collects data about homicide, it is not analyzed here. Other more complete and detailed national data 
sets on this crime are available and have been analyzed elsewhere (Finkelhor, 1997; Finkelhor and Ormrod, in press).

In addition to information about the victim and type of offense, NIBRS reports a wealth of details about the circumstances of an incident. Among other particulars, incident time and location are recorded, facts about perpetrators are listed, use of weapons and weapon types are noted, and stolen property is cataloged. Thus, NIBRS provides information for a fuller description of juvenile victimizations coming to the attention of the police, both in terms of victim characteristics and incident attributes, than was previously available in the UCR. ${ }^{1}$

\section{Juvenile and Adult Victims}

Juveniles make up 12 percent of all the crime victims reported in the police jurisdictions providing NIBRS data, notably less than the percentage of juveniles in both the total U.S. population (26 percent) and the States currently represented in NIBRS (also 26 percent). Individual crimes vary a great deal in their proportion of juvenile victims (figure 1). For two crimes in particular, sex offenses and kidnaping, juveniles make up a quite disproportionate portion of the victim population. Juveniles constitute smaller proportions of the victims of the following crime categories: aggravated assault (19 percent), simple assault (19 percent), robbery (14 percent), homicide (12 percent), larceny (8 percent), vandalism (4 percent), and motor vehicle theft (2 percent). The low percentage for motor vehicle theft is obviously related to the small number of juveniles who own motor vehicles. Overall, juveniles make up 22 percent of violent crime victims and 6 percent of property crime victims (when individuals rather than institutions are identified as victims).

In addition to the percentage of juvenile victims for various crimes, NIBRS data can also provide a perspective on the mix of different kinds of crimes being reported by juveniles (figure 2 ). Simple assault is by far the most common crime committed against juveniles, constituting 41 percent of all offenses against juveniles

\footnotetext{
${ }^{1}$ Victims or offenders involved in multiple incidents in a given year will appear in the NIBRS database more than once, counted as separate victims and offenders. Thus, NIBRS data may overrepresent characteristics of victims and offenders who appear more frequently.
}

known to police. After that, in decreasing order of magnitude, are larceny, sex offenses, aggravated assault, vandalism, robbery, kidnaping, motor vehicle theft, and homicide. There is a set of additional property crimes, such as burglary, arson, and fraud, with a small number of juvenile victims recorded in NIBRS. These crimes are categorized as "all others" in figure 2 , but, along with homicide, are not discussed individually in this Bulletin.

Although sexual assault is the crime with the highest percentage of juvenile victims, it is the third most common juvenile crime reported, behind simple assault and larceny. This is true, even with female victims, for whom sex offenses constitute 35 percent of all the reported victimizations. Therefore, while sex crimes against juveniles receive a lion's share of public attention, they constitute a minority of the offenses against juveniles that are reported.

Gender disparities among juvenile crime victims parallel gender differences for crime victims in general (figure 3 ). Girls outnumber boys as victims of sex offenses ( 82 percent and 18 percent, respectively) and kidnaping (63 percent and 37 percent, respectively), while boys outnumber girls as victims of robbery (81 percent and 19 percent, respectively) and larceny (69 percent and 31 percent, respectively). Overall, boys are somewhat more likely to be victimized than girls (55 percent and 45 percent, respectively), which is approximately the gender ratio for the

\section{The National Incident-Based Reporting System}

The U.S. Department of Justice is replacing its long-established Uniform Crime Report (UCR) system with a more comprehensive National Incident-Based Reporting System (NIBRS). While the UCR monitors only a limited number of index crimes and, with the exception of homicides, gathers few details on each crime event, the NIBRS system collects a wide range of information on victims, offenders, and circumstances for a greatly increased variety of offenses. Offenses tracked in NIBRS include violent crimes (e.g., homicide, assault, rape, robbery), property crimes (e.g., theft, arson, vandalism, fraud, embezzlement), and crimes against society (e.g., drug offenses, gambling, prostitution). Moreover, NIBRS collects information on multiple victims, multiple offenders, and multiple crimes that may be part of the same episode.

Under the new system, as with the old, local law enforcement personnel compile information on crimes coming to their attention, and this information is aggregated in turn at the State and national levels. For a crime to be counted in the system, it simply needs to be reported and investigated. It is not necessary that an incident be cleared or an arrest made, although unfounded reports are deleted from the record.

NIBRS holds great promise, but it is still far from a national system. Its implementation by the FBI began in 1988, and participation by States and local agencies is voluntary and incremental. By 1995, jurisdictions in 9 States had agencies contributing data; by 1997 , the number was 12 , and by the end of 1999, jurisdictions in 17 States submitted reports, providing coverage for 11 percent of the Nation's population and 9 percent of its crime. Only three States (Idaho, lowa, and South Carolina) have participation from all local jurisdictions, and only one city with a population greater than 500,000 (Austin, $\mathrm{TX}$ ) is reporting. The crime experiences of large urban areas are particularly underrepresented. The system, therefore, is not yet nationally representative nor do findings represent national trends or national statistics. Nevertheless, the system is assembling large amounts of crime information and providing a richness of detail about juvenile victimizations previously unavailable. The patterns and associations these data reveal are real and represent the experiences of a large number of youth. For 1997 , the 12 participating States reported a total of $1,043,719$ crimes against individuals, with 119,852 occurring against juveniles. Nevertheless, patterns may change as more jurisdictions join the system.

More information about NIBRS data collection can be found at these Web sites: (1) www.jrsa.org/ibrrc/, (2) www.fbi.gov/ucr/nibrs/manuals/v1all.pdf, (3) www.fbi.gov/ucr/nibrs.htm, and (4) www.nibrs.search.org/. 
most common juvenile victimizationsimple assault.

Comparisons of figure 1 and figure 3 show sex offenses as the crime with the highest proportion of juvenile victims and also the highest proportion of female victims. However, an examination of the gender and age patterns of specific sex crimes shows some variability (figure 4). For forcible rape, juveniles constitute about half of the female victims, whereas for forcible fondling and incest, they represent close to 80 percent or more. (Statutory rape is by definition a crime against juveniles.) For male sexual assault victims, there is less variability by type of sex offense. Juveniles account for almost 90 percent of male victims in every type of sex crime. Thus, in terms of what comes to the attention of police in NIBRS jurisdictions, male sexual victimization almost entirely involves juveniles.

Juvenile crime victims are slightly more likely to be from minority backgrounds than adult victims (22 percent and 19 percent, respectively). Compared with levels reported for "all crimes," minority juveniles are particularly overrepre-

\section{Figure 3: Juvenile Victimization, by Type of Crime and Victim's Gender}

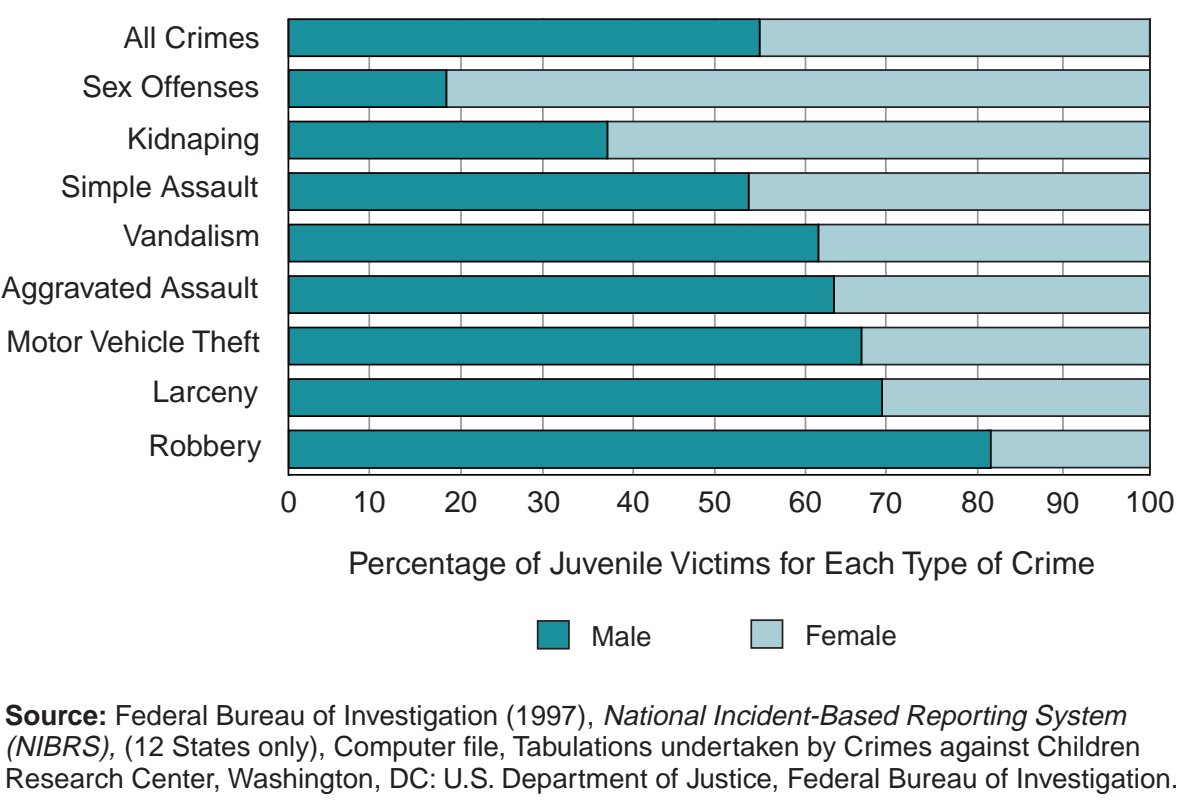

sented relative to white juveniles as victims of violent crimes, especially aggravated assault and robbery (figure 5).
They are underrepresented as victims of the property crimes of larceny, vandalism, and motor vehicle theft.

\section{The Crimes against Children Research Center}

The Crimes against Children Research Center (CCRC) helps young victims of crime by providing high quality research, statistics, and education to the public, policymakers, law enforcement personnel, and various other child welfare practitioners. The crimes of concern to CCRC include physical and sexual abuse, abduction, homicide, rape, assault, property offenses, and the victimization of children on the Internet. CCRC activities include:

- Preparing policy reports on key current issues.

- Analyzing national and local statistics on crimes against children.

- Developing assessment tools for practitioners and researchers.

- Promoting crime reporting and help-seeking by and increased services for crime victims.

- Evaluating state-of-the-art prevention and intervention programs.

- Sponsoring conferences, workshops, institutes, and courses for practitioners and researchers.

- Monitoring and interpreting trends.

The Crimes against Children Research Center was created in 1998 at the University of New Hampshire. It grew out of and expands upon the work of the Family Research Laboratory, which has been devoted to the study of family violence, child victimization, and related topics since 1975. Initial funding for CCRC was provided by the U.S. Department of Justice, Office of Justice Programs, Office of Juvenile Justice and Delinquency Prevention. CCRC also draws on funding from grants, individual gifts, revenues from publications and programs, and State and Federal sources. CCRC staff include internationally recognized experts who have published numerous books and articles concerning the incidence and impact of violence against children.

The Center's current projects include the first national study of youth victimization experiences on the Internet; a national evaluation of children's advocacy centers, multidisciplinary agencies that are designed to reduce trauma to children whose crime victimization is being investigated and prosecuted; and the development of a screening tool to help researchers and practitioners better identify child crime victims.

A list of CCRC publications is available online at www.unh.edu/ccrc/pubs.html. For further information contact:

Crimes against Children Research Center

Family Research Laboratory

University of New Hampshire

Durham, NH 03824

603-862-1888

Internet: www.unh.edu/ccrc/ 


\section{Figure 4: Juvenile Sexual Victimization, by Type of Crime, Victim's Gender, and Victim's Age Group}

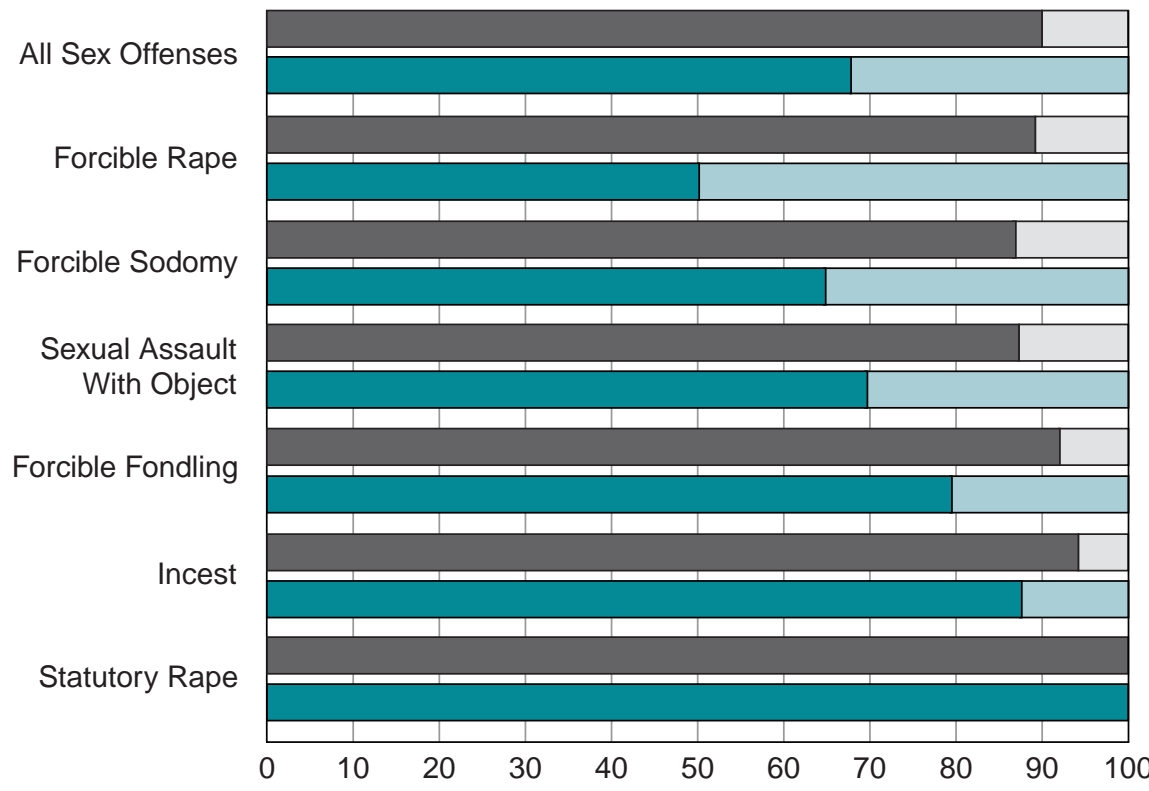

Percentage of All Male or Female Victims for Each Type of Crime

Male (Juvenile/Adult)

Female (Juvenile/Adult)

Source: Federal Bureau of Investigation (1997), National Incident-Based Reporting System (NIBRS), (12 States only), Computer file, Tabulations undertaken by Crimes against Children Research Center, Washington, DC: U.S. Department of Justice, Federal Bureau of Investigation.

\section{Figure 5: Juvenile Victimization, by Type of Crime and Victim's Race or Ethnicity}

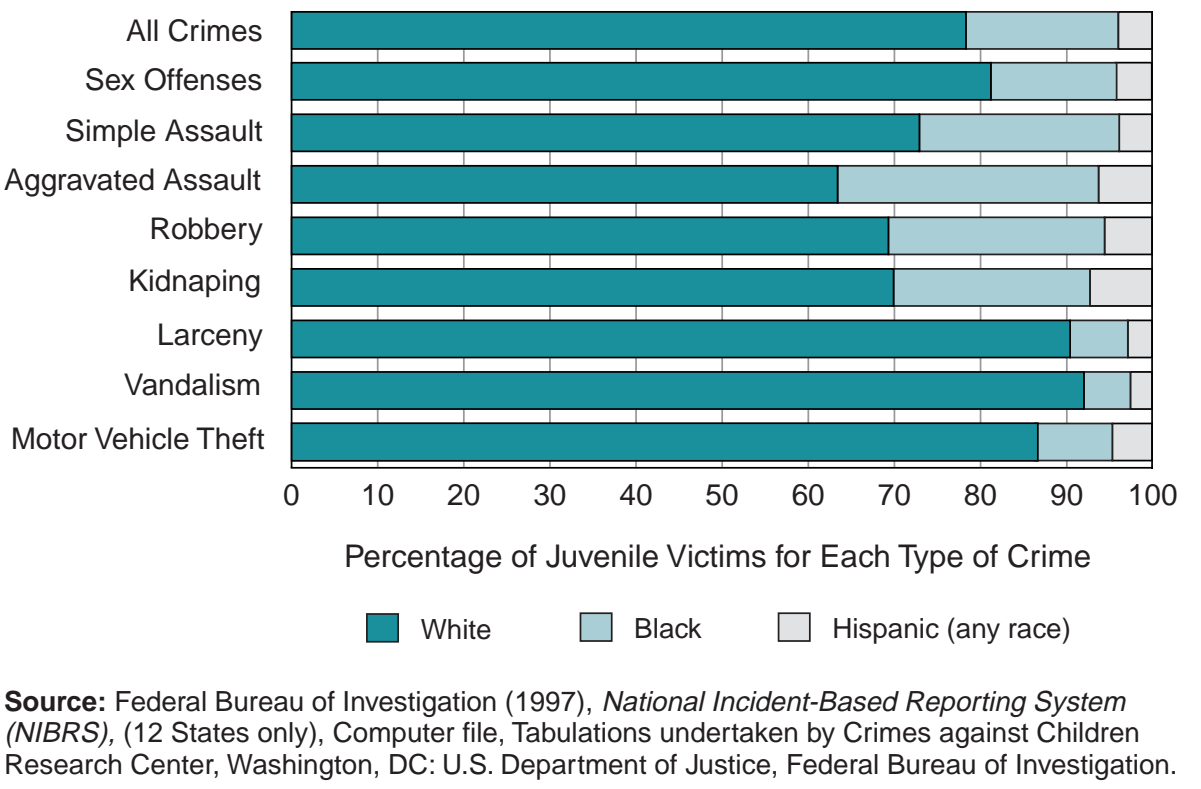

\section{Crime Victimization and the Stages of Childhood}

Childhood is a period characterized by dramatic developmental changes, so generalizations about all juvenile victims must be tempered by a recognition of the effects of age differences. Crimes need to be analyzed as to how they are distributed across the various stages of childhood, an exercise elsewhere called "developmental victimology" (Finkelhor, 1995). This Bulletin uses the year-by-year age categories available in NIBRS to capture these different patterns.

Substantially more crime is reported for teenagers (youth ages 12 to 17) than for preteens (youth ages 11 and younger) (figure 6). Teenagers account for 78 percent of all juvenile crime victimizations reported by NIBRS jurisdictions. However, it is not certain to what extent teenagers are actually more victimized than younger children. Many self-report studies, including the NCVS, show uniformly high rates of victimization for younger (ages 12-14) and older (ages 15-17) teenagers, and some studies show rates nearly as high for children ages 10 and 11 (Finkelhor, 1998). Thus, the association between victimization and age shown in figure 6 may be an effect of the less frequent reporting of crimes involving younger victims to the police. NCVS data clearly show that older teenagers are more likely than younger teenagers (and presumably preteens) to report crimes to the police (Finkelhor and Ormrod, 1999). Combining this with the finding that overall crimes against juveniles are less likely to be reported to police than crimes against adults suggests that police data in general and NIBRS data in particular are not good indicators of the true burden of crime victimization by age group, but only the relative proportions of these victimizations that police are likely to encounter.

From this reported-crime vantage point, some crimes, like kidnaping, have a relatively large number of preteen victims (57 percent). Others, like robbery, have relatively few (14 percent). Figure 7 suggests that there are three broad patterns of police-reported juvenile crime victimization that emerge when NIBRS data are examined by the victim's age group. There are crimes that are reported almost exclusively by teenagers and rarely by preteens (less than 10 percent), what might be called the "teen-exclusive" pattern, motor 


\section{NIBRS Compared to UCR and NCVS}

Since the National Incident-Based Reporting System (NIBRS) does not provide national coverage, it is reasonable to ask whether the patterns found in its records are consistent with those of true national data sets. In particular, it is worth considering how closely NIBRS patterns match equivalent patterns derived from the Uniform Crime Reporting (UCR) system and National Crime Victimization Survey (NCVS), both of which are nationally representative. The presence of parallel data would suggest the degree to which the NIBRS jurisdictions are consistent with overall national patterns.

UCR tallies only the total number of crimes known to police, tracking a selected set of "index" offenses, including homicide, forcible rape, robbery, aggravated assault, burglary, larceny, and motor vehicle theft. With the exception of homicide, it assembles no information on the details of crime incidents. While UCR and NIBRS cannot be compared on specific victim characteristics, their relative counts can be matched, revealing that the relative numbers of index crimes reported in 1997 by UCR and NIBRS are generally proportionate (table 1). The relative underreporting of robbery and motor vehicle theft by NIBRS compared to UCR may reflect the absence of large urban areas among the NIBRS reporting jurisdictions. The greater relative frequency of larceny in NIBRS statistically compensates for the underreporting of these offenses.

Crime victimizations reported in NCVS also share similarities with patterns present in the NIBRS data. NCVS collects detailed information on incidents and victims, allowing more focused comparisons with NIBRS than are possible with UCR. For example, a comparison of the relative number of adult and juvenile victims for violent crimes known to police yields notable parallels (table 2). "All violent crime," "robbery," and "assault" have quite similar proportions of adult and juvenile victims in both data sets. Only forcible sex offenses show differences between the two, with the proportions of adult and juvenile sex victimizations more equal in NIBRS than NCVS.
The correspondencies found in both of these comparisons suggest that, while NIBRS data cannot be assumed to be nationally representative, they nevertheless exhibit important similarities to national crime victimization patterns.

Table 1: Comparison of Crime Patterns in NIBRS and UCR, 1997

\begin{tabular}{lcc} 
& \multicolumn{2}{c}{ Percent Distribution } \\
\cline { 2 - 3 } Crime Index Offense & UCR & NIBRS \\
\hline Homicide & 0.1 & 0.1 \\
Forcible Rape & 0.7 & 0.8 \\
Robbery & 3.8 & 1.8 \\
Aggravated Assault & 7.8 & 7.2 \\
Burglary & 18.7 & 18.2 \\
Larceny & 58.6 & 64.7 \\
Motor Vehicle Theft & 10.3 & 7.2
\end{tabular}

Notes: UCR tabulations contain "estimations" in some circumstances. UCR counts apply a "hierarchy rule" where only the most serious offense is counted in multiple offense, multiple victim incidents; therefore, NIBRS incidents were evaluated for most serious offense. UCR covers 95 percent of the U.S. population. In UCR, forcible rape only includes female victims; therefore, male rape victims were excluded from NIBRS counts. UCR offense codes and NIBRS offense codes are identical.

Sources: Federal Bureau of Investigation (1997), National Incident-Based Reporting System (NIBRS), (12 States only), Computer file, Tabulations undertaken by the Crimes against Children Research Center, Washington, DC: U.S. Department of Justice, Federal Bureau of Investigation. Federal Bureau of Investigation (1997), Uniform Crime Reports for the United States, 1997, Washington, DC: U.S. Department of Justice, Federal Bureau of Investigation.

Table 2: Comparison of Victim Ages in NCVS and NIBRS, 1997

\begin{tabular}{llcr} 
& & \multicolumn{2}{c}{ Percent Distribution } \\
\cline { 3 - 4 } Offense Type & Victim Age Group & NCVS & NIBRS \\
\hline All Violent Crime & & 16 & 17 \\
& Juvenile & 84 & 83 \\
\multirow{2}{*}{ Robbery } & Adult & 13 & 12 \\
& Juvenile & 87 & 88 \\
Assault & Adult & 16 & 16 \\
& & 84 & 84 \\
Forcible Sex & Juvenile & & \\
& Adult & 34 & 53 \\
& Juvenile & 66 & 47
\end{tabular}

Notes: NCVS only interviews persons 12 years of age and older; therefore, juveniles younger than 12 were excluded from NIBRS counts. NIBRS records only incidents known to police; therefore, only such incidents from NCVS are used.

Sources: Federal Bureau of Investigation (1997), National Incident-Based Reporting System (NIBRS), (12 States only), Computer file, Tabulations undertaken by the Crimes against Children Research Center, Washington, DC: U.S. Department of Justice, Federal Bureau of Investigation. Bureau of Justice Statistics (1999), National Crime Victimization Survey, 1992-1997, Computer file, seventh edition, Survey conducted by U.S. Department of Commerce, Bureau of the Census, Ann Arbor, MI: Inter-University Consortium for Political and Social Research. 
vehicle theft being the classic case. There are other crimes, such as kidnaping, that are reported across all stages of childhood with both teens and preteens, including many preschoolers, experiencing substantial levels of victimization, what might be called a "transchildhood" pattern. Finally, there are crimes that are reported disproportionately among teens but also to some modest degree (more than 10 percent) among preteens, what might be called a "teen-predominant" pattern, which would describe the pattern for simple and aggravated assault.

Individual sex crimes can also be characterized with these patterns (figure 8). Statutory rape is a teen-exclusive pattern crime. Forcible sodomy, sexual assaults with objects, forcible fondling, and incest all appear to be transchildhood pattern crimes, with substantial proportions of victims ages 6 to 11 and even younger. Forcible rape conforms to the teen-predominant pattern, with approximately 24 percent of victims younger than age 12 . Of course, these patterns are not necessarily illustrative of the true distribution of crime because they reflect patterns of reporting and may also be influenced by the way crimes are defined or classified.

\section{Perpetrators Against Juveniles}

As figure 9 shows, in incidents where knowledge of perpetrators allows their identification as family member, acquaintance, or stranger, most offenders against juveniles ( 80 percent) are known to the victim (i.e., the offender is a family member or an acquaintance). Only 11 percent of the child victimizers in violent crimes are strangers, suggesting that while "stranger danger" may be an important concept in child safety training, it is far from sufficient. There are two violent crimes with relatively higher percentages of stranger perpetrators-kidnaping (24 percent) and robbery (52 percent). Kidnaping, however, also has a relatively high percentage of family offenders (38 percent) as do sex offenses (28 percent). Despite the stereotypes about stranger molesters and rapists, sex offenses are the crimes least likely to involve strangers as perpetrators.

Juveniles are more likely than adults to be victimized by other juveniles, but their victimization is much less exclusively at the hands of juveniles than might be

\section{Figure 6: Juvenile Victimization (All Crimes), by Victim's Age and Victim's Gender}
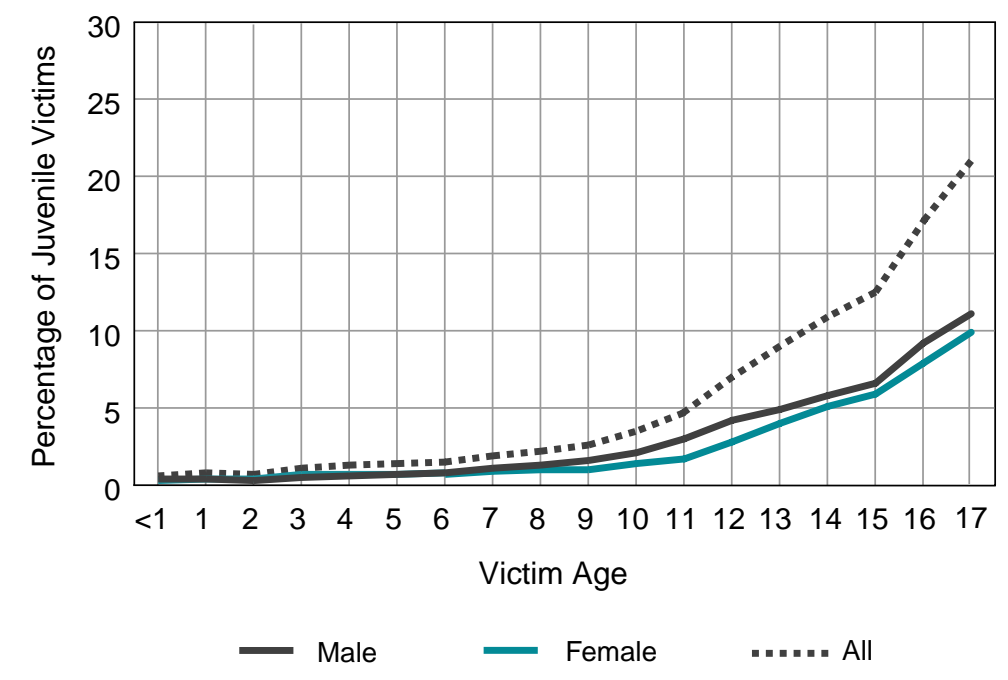

Source: Federal Bureau of Investigation (1997), National Incident-Based Reporting System (NIBRS), (12 States only), Computer file, Tabulations undertaken by Crimes against Children Research Center, Washington, DC: U.S. Department of Justice, Federal Bureau of Investigation.

\section{Figure 7: Juvenile Victimization, by Type of Crime and Victim's Age Group}

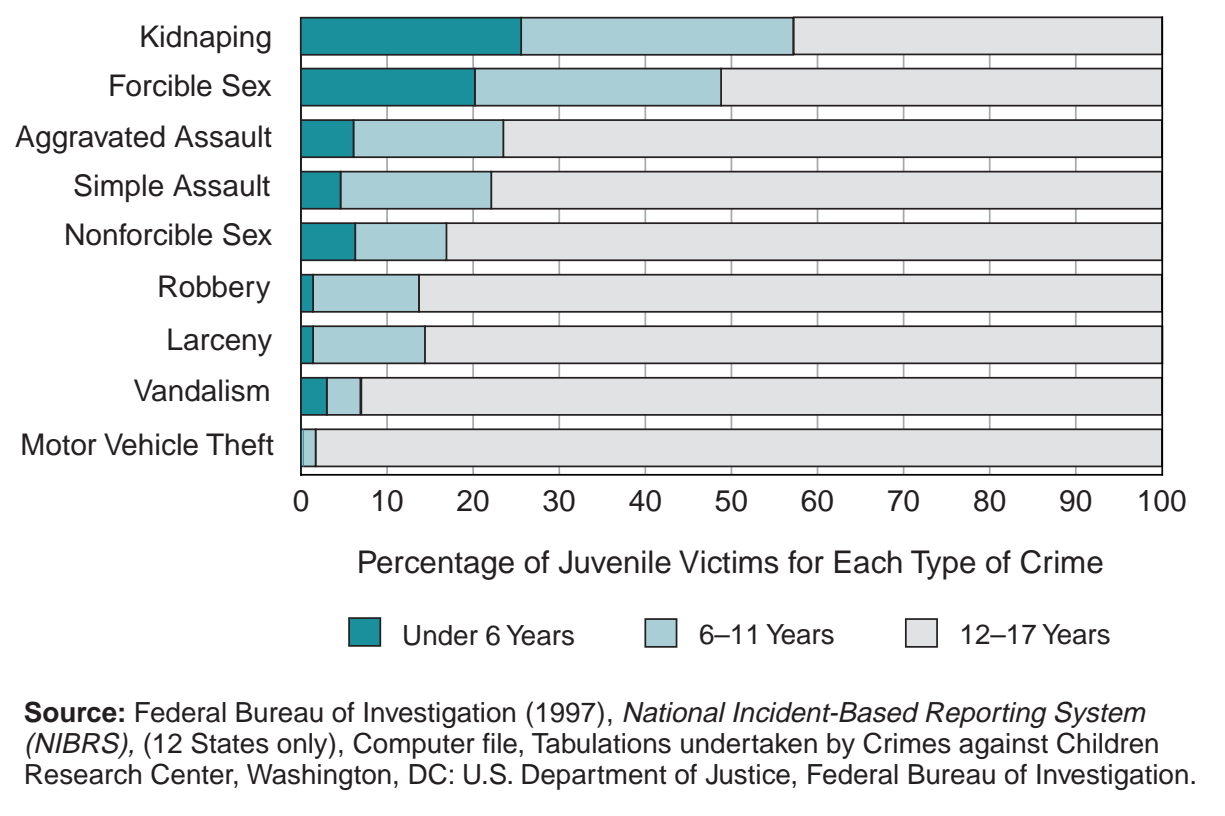

imagined. Adults are responsible for 55 percent of the juvenile victimizations known to police and constitute 47 percent of all identified offenders against juveniles. However, NIBRS data may exaggerate the percentage of adult offenders, because adult-perpetrated crimes are more likely than juvenile-perpetrated crimes to be reported to the police, a reality reflected in the NCVS self-reported data (Finkelhor and Ormrod, 1999).

In the NIBRS jurisdictions, the percentage of adult perpetrators is highest for kidnaping and sex offenses against juveniles, consistent with the stereotype, but there 


\section{Figure 8: Juvenile Sexual Victimization, by Type of Crime and Victim's Age Group}

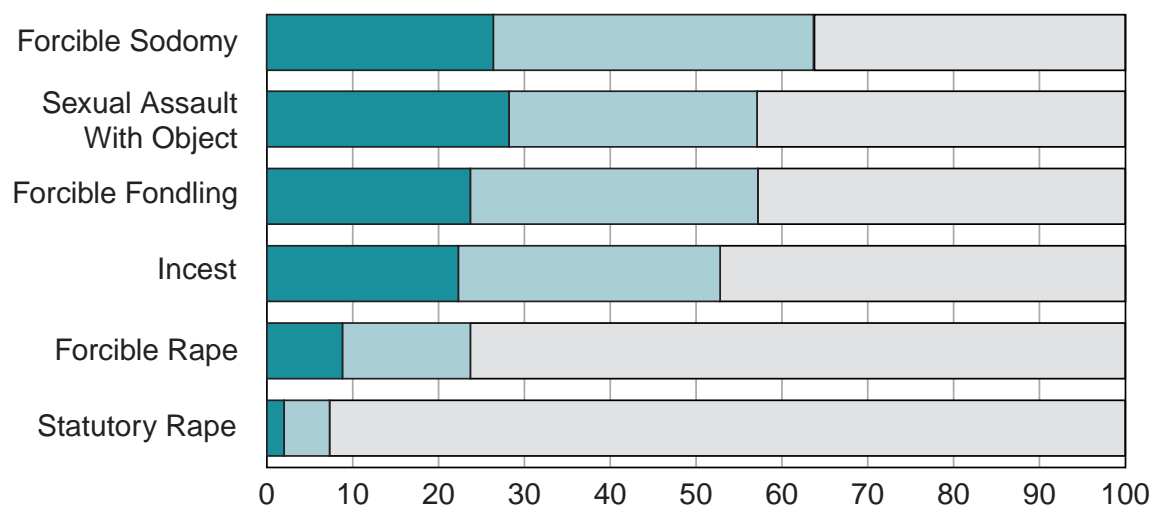

Percentage of Juvenile Victims for Each Type of Crime

Under 6 Years $\quad \square 6-11$ Years $\quad \square$ 12-17 Years

Source: Federal Bureau of Investigation (1997), National Incident-Based Reporting System (NIBRS), (12 States only), Computer file, Tabulations undertaken by Crimes against Children Research Center, Washington, DC: U.S. Department of Justice, Federal Bureau of Investigation.

\section{Figure 9: Juvenile Victimization, by Type of Crime and Offender's Relationship to the Victim}

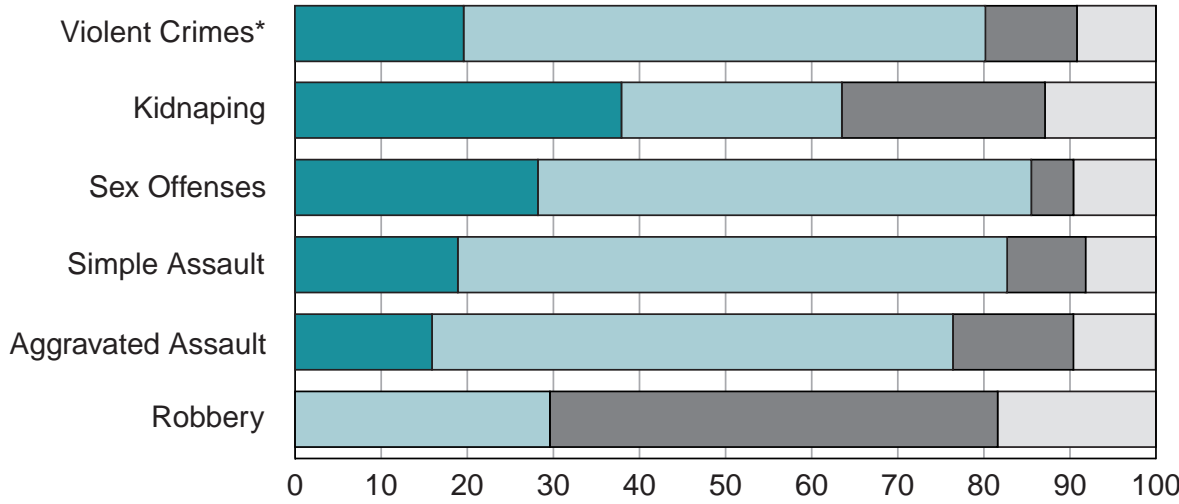

Percentage of All Offenders Against Juveniles for Each Type of Crime

$$
\text { Family } \square \text { Acquaintance } \square \text { Stranger } \square \text { Unidentified }
$$

* Includes nonforcible sex offenses. Property crimes other than robbery are excluded here because most property crime offenders remain unidentified, and therefore, these offender patterns are likely to be unreliable.

Source: Federal Bureau of Investigation (1997), National Incident-Based Reporting System (NIBRS), (12 States only), Computer file, Tabulations undertaken by Crimes against Children Research Center, Washington, DC: U.S. Department of Justice, Federal Bureau of Investigation. is no specific crime, not even simple assault, for which the percentage of adult perpetrators (among all identified perpetrators) falls below 40 percent (figure 10). Thus, a substantial portion of the crimes reported to police involving child victims are cases that have the potential to be processed in the criminal (as opposed to juvenile) court. Conversely, kidnaping and sex crimes against juveniles have a certain number of juvenile perpetrators (12 percent and 36 percent, respectively), something not necessarily reflected in the stereotypes of these crimes.

The characteristics of perpetrators change quite dramatically, depending on the age of the victim (figure 11). For example, family perpetrators commit most of the reported crimes against juveniles younger than age 5 , but this percentage declines steadily until adolescence, when family members constitute less than 20 percent of all perpetrators. In a nearly mirror opposite trend, the percentage of acquaintance perpetrators rises throughout childhood, reaching a steady level of approximately 70 percent for victims ages 12 and older. The percentage of perpetrators who are strangers also rises slightly, but not dramatically, as juvenile victims grow older and spend more time in public areas.

In NIBRS incident reports, the ratio of adult perpetrators to juvenile perpetrators also changes with the age of the victim (figure 12). Adult perpetrators predominate for children younger than age 7 , but during school years juvenile perpetrators prevail, until the late teenage years. Then, as juvenile victims come closer to maturity and more of their peers reach adulthood (age 18), the level of adult perpetration rises once again. It may also be that as juvenile offenders reach adult status, they are more likely to be reported to the police, a pattern suggested by an analysis of NCVS data on reporting (Finkelhor and Ormrod, 1999).

Figure 13 combines the offender's age (juvenile or adult) and relationship to the victim (family, acquaintance, or stranger) to show some more specific victimization patterns for juveniles at different stages of childhood. Whereas the percentage of adult family perpetrators (dark green solid line) shows a steady decline as children grow older (as suggested in figure 11), the 
percentage of juvenile family perpetrators (black dashed line) follows a different pattern. Incidents involving juvenile family offenders (mostly brothers and sisters) increase a bit after infancy (while incidents of parent perpetration are declining) and then remain elevated for victims ages 3 to 8 , after which they, too, subside. Adult and juvenile acquaintance perpetrators also show different patterns. Juveniles account for most of the increase in incidents committed by acquaintance perpetrators against children 8 and younger (medium gray dashed line). During that same time, adult acquaintance perpetration-which is quite high for preschoolers-declines to a slight degree (medium green solid line). However, starting in adolescence, offenses committed by juvenile acquaintances decline dramatically, while crimes perpetrated by adult acquaintances dramatically increase. Offenses committed by strangers also have different patterns for juvenile and adult perpetrators. Adult strangers (light green solid line) pose the biggest risk to infants and youth in their late teens. Juvenile strangers (light gray dashed line) pose the greatest peril to victims in the late elementary school years.

In contrast with their levels in official child abuse statistics (U.S. Department of Health and Human Services' Children's Bureau, 1999), female offenders are relatively scarce in data from NIBRS jurisdictions on crimes against juveniles. They constitute 24 percent of the offenders in violent crimes against juveniles, only slightly higher than their proportion of offenders in crimes against adults. Females constitute 36 percent of offenders in violent crimes against children younger than age 1 and a minority of the offenders committing sex offenses against juvenile male victims. This suggests that female-perpetrated child abuse is less likely than male-perpetrated child abuse to be reported to the police by child welfare authorities, a conclusion suggested by early data from the child welfare system itself (Finkelhor, 1983).

\section{Preteen Victims}

One of the biggest opportunities data from NIBRS jurisdictions provide is the possibility of looking at crimes against children under age 12, a segment of the population that is not covered by the extensive selfreport crime victimization information that has been available from the NCVS.

\section{Figure 10: Juvenile Victimization, by Type of Crime and Offender's Age Group}

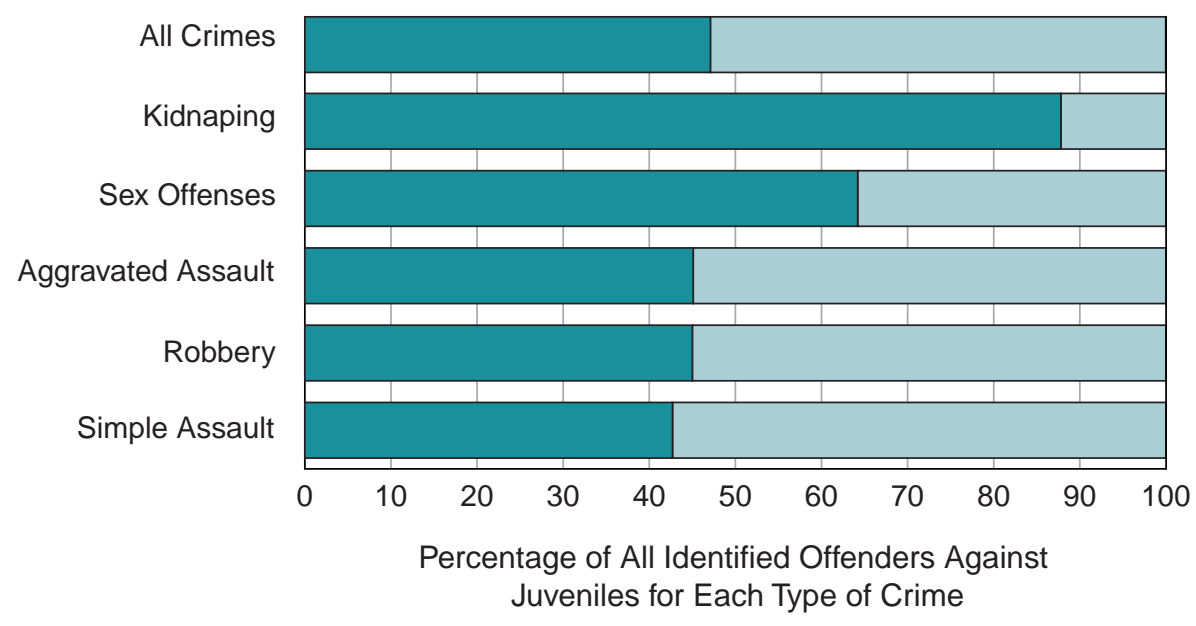

Adult

Juvenile

Source: Federal Bureau of Investigation (1997), National Incident-Based Reporting System (NIBRS), (12 States only), Computer file, Tabulations undertaken by Crimes against Children Research Center, Washington, DC: U.S. Department of Justice, Federal Bureau of Investigation.

Figure 11: Juvenile Victimization (All Crimes), by Victim's Age and Offender's Relationship to the Victim

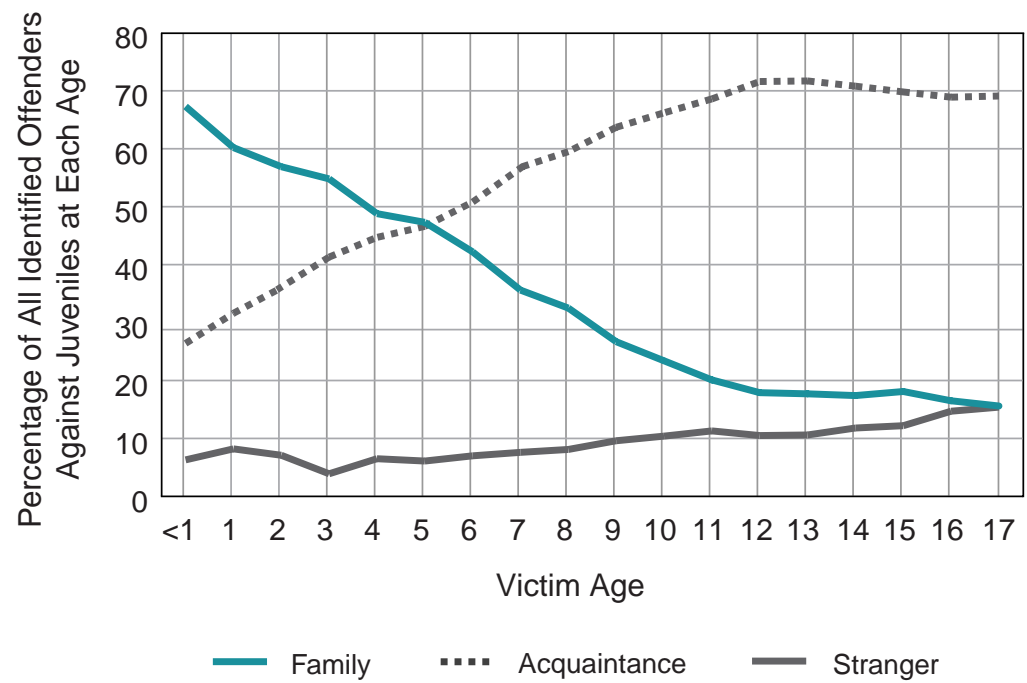

Source: Federal Bureau of Investigation (1997), National Incident-Based Reporting System (NIBRS), (12 States only), Computer file, Tabulations undertaken by Crimes against Children Research Center, Washington, DC: U.S. Department of Justice, Federal Bureau of Investigation. 


\section{Figure 12: Juvenile Victimization (All Crimes), by Victim's Age and Offender Age Group}

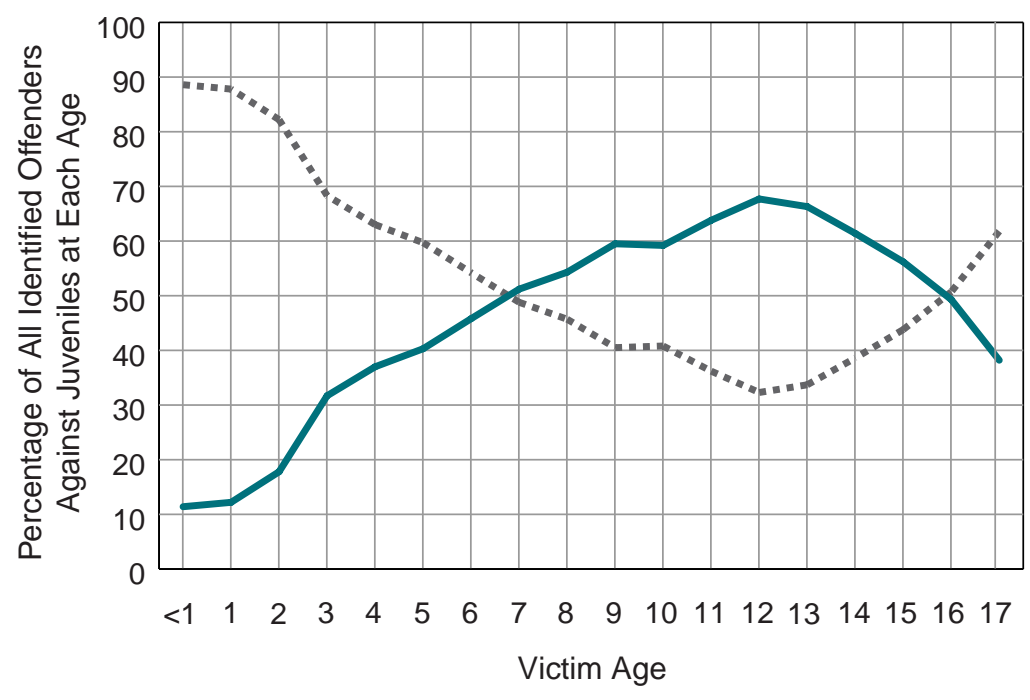

— Juvenile Offender \#.". Adult Offender

Source: Federal Bureau of Investigation (1997), National Incident-Based Reporting System (NIBRS), (12 States only), Computer file, Tabulations undertaken by Crimes against Children Research Center, Washington, DC: U.S. Department of Justice, Federal Bureau of Investigation.

\section{Figure 13: Juvenile Victimization (All Crimes), by Victim's Age, Offender's Age Group, and Offender's Relationship to the Victim}

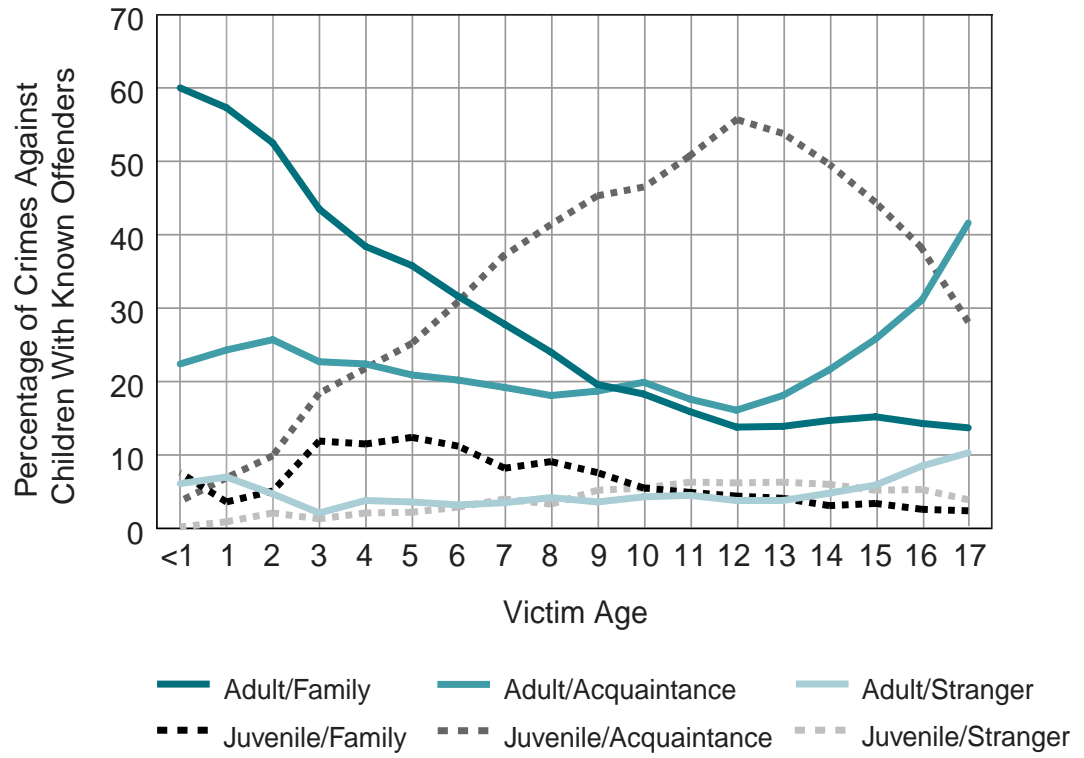

Source: Federal Bureau of Investigation (1997), National Incident-Based Reporting System (NIBRS), (12 States only), Computer file, Tabulations undertaken by Crimes against Children Research Center, Washington, DC: U.S. Department of Justice, Federal Bureau of Investigation.
Although children younger than age 12 represent only a small percentage of all reported victims ( 3 percent of all crimes and 6 percent of crimes against persons), their crime profile is unusual (table 3 ). Sexual assault accounts for almost onethird of this preteen victimization, more than twice the proportion for older juveniles, and family offenders make up onethird of the offenders against this group, twice the proportion for older juveniles. The familial and sexual nature of the crimes underscores some of the challenges this victim group poses for law enforcement. Victim and family cooperation with law enforcement is often problematic, as is the need to mitigate victim distress and trauma.

\section{Conclusion}

If patterns of crime against juveniles in the rest of the country parallel the patterns from the jurisdictions now reporting to NIBRS, it would appear that crimes against juveniles constitute about oneeighth of all the crimes currently reported to law enforcement officials. However, these crimes carry special burdens. More than 70 percent of reported sex offenses involve juvenile victims. Moreover, crimes against children involve special investigatory and prosecutorial challenges. Some of these relate to the young age of victims-approximately onequarter of juvenile victims are under age 12. Some of these relate to the intimate character of the perpetrators, 20 percent of whom are family and 61 percent of whom are acquaintances.

The developing NIBRS database offers some welcome opportunities for analyzing and tracking this special category of crime victims. For example, it allows analysis of changes in crime victimization patterns across the stages of childhood. It also offers opportunities to look at special offender categories, such as parents and caretakers (Finkelhor and Ormrod, in press).

The system may be able to highlight some obvious needs for law enforcement attention or training. For example, in recent years, sex offenses have been the major focus of those concerned with juvenile victims, but data from NIBRS jurisdictions reveal that aggravated assaults against juveniles are reported at about the same 
Table 3: Preteen and Teenage Crime Victimization Patterns

\begin{tabular}{lcc} 
& \multicolumn{2}{c}{ Victim Age Group } \\
\cline { 2 - 3 } Outcome & Preteen $(<\mathbf{1 2}$ years) & Teenage (12-17 years) \\
\hline Type of Crime & $\mathbf{n = 2 1 , 6 7 6 ~ o f f e n s e s ~}$ & $\mathbf{n = 5 8 , 9 5 8}$ offenses \\
Aggravated assault & $15 \%$ & $17 \%$ \\
Simple assault & 50 & 65 \\
Forcible sex offenses & 30 & 12 \\
Nonforcible sex offenses & 1 & 2 \\
Kidnaping & 3 & 1 \\
Robbery & 1 & 3 \\
All offenses & 100 & 100 \\
Relationship to Offender & & $\mathbf{n = 6 1 , 3 6 2}$ offenders \\
Family & $\mathbf{n = 2 1 , 0 6 8}$ offenders & $17 \%$ \\
Acquaintance & $35 \%$ & 70 \\
Stranger & 56 & 13 \\
All offenses & 9 & 100
\end{tabular}

Source: Federal Bureau of Investigation (1997), National Incident-Based Reporting System (NIBRS), (12 States only), Computer file, Tabulations undertaken by Crimes against Children Research Center, Washington, DC: U.S. Department of Justice, Federal Bureau of Investigation.

frequency. Little is known about the needs of such victims and the handling of their victimizations by the criminal and juvenile justice systems. In years to come, NIBRS should prove to be a valuable tool for researchers and practitioners interested in improving public policies toward juvenile victims.

\section{References} Prosecuting the offender in cases of
Finkelhor, D. 1995. The victimization of children in a developmental perspective. American Journal of Orthopsychiatry 65(2):177-193.

Finkelhor, D. 1997. The homicide of children and youth: A developmental perspective. In Out of the Darkness: Contemporary Research Perspectives on Family Violence, edited by G.K. Kantor and J. Jasinski. Thousand Oaks, CA: Sage Publications, pp. 17-34.

Finkelhor, D. 1998. The responses of preadolescents and adolescents in a national victimization survey. Journal of Interpersonal Violence 13(3):362-382.

Finkelhor, D., and Ormrod, R. 1999. Reporting Crimes Against Juveniles. Bulletin. Washington, DC: U.S. Department of Justice, Office of Justice Programs, Office of Juvenile Justice and Delinquency Prevention.

Finkelhor, D. and Ormrod, R. In press. Child Abuse and Neglect Reported to Police: The NIBRS Perspective. Bulletin. Washington, DC: U.S. Department of Justice, Office of Justice Programs, Office of Juvenile Justice and Delinquency Prevention.

Finkelhor, D. 1983. Removing the childsexual abuse: Evidence from the national reporting system for child abuse and neglect. Child Abuse \& Neglect 7:195-205.
U.S. Department of Health and Human Services' Children's Bureau. 1999. Child Maltreatment 1997: Reports From the States to the National Child Abuse and Neglect Data System. Washington, DC: U.S. Government Printing Office. 
Washington, DC 20531

Official Business

Penalty for Private Use $\$ 300$

This Bulletin was prepared under grant number 98-JN-FX-0012 from the Office of Juvenile Justice and Delinquency Prevention, U.S. Department of Justice.

Points of view or opinions expressed in this document are those of the authors and do not necessarily represent the official position or policies of OJJDP or the U.S. Department of Justice.

The Office of Juvenile Justice and Delinquency Prevention is a component of the Office of Justice Programs, which also includes the Bureau of Justice Assistance, the Bureau of Justice Statistics, the National Institute of Justice, and the Office for Victims of Crime.

\section{Acknowledgments}

This Bulletin was prepared by David Finkelhor, Ph.D., Professor of Sociology, and Director, Crimes against Children Research Center, University of New Hampshire, david.finkelhor@unh.edu (e-mail); and Richard Ormrod, Ph.D., Research Scientist, Crimes against Children Research Center, University of New Hampshire, rormrod@cisunix.unh.edu (e-mail).

\section{Share With Your Colleagues}

Unless otherwise noted, OJJDP publications are not copyright protected. We encourage you to reproduce this document, share it with your colleagues, and reprint it in your newsletter or journal. However, if you reprint, please cite OJJDP and the authors of this Bulletin. We are also interested in your feedback, such as how you received a copy, how you intend to use the information, and how OJJDP materials meet your individual or agency needs. Please direct your comments and questions to: 